\title{
GESTÃO DO CONHECIMENTO: CONTRIBUIÇÕES E POSSIBILIDADES PARA O CORPO DE BOMBEIROS MILITAR
}

\author{
Luiz Augusto de Medeiros Lira ${ }^{1}$ \\ Ibsen Mateus Bittencourt Santana Pinto ${ }^{2}$
}

\section{RESUMO}

O conhecimento é um ativo valioso para as organizações e, como tal, deve ser adequadamente gerenciado. Neste viés, a Gestão do Conhecimento se apresenta como alternativa viável para a otimização do desempenho de organizações públicas e privadas, à medida que garante a utilização do capital intelectual de uma forma sistemática e planejada. O presente trabalho teve por objetivo esclarecer os benefícios e a aplicabilidade da Gestão do Conhecimento para o Corpo de Bombeiros Militar. Para tanto, mediado pela pesquisa bibliográfica e documental, foram exploradas diferentes iniciativas de Gestão do Conhecimento, formalmente reconhecidas, em organizações nas áreas de defesa e segurança pública, no Brasil e no exterior. Como resultado, foram mapeados 7 casos internacionais e 12 nacionais, cujo exame permitiu a identificação de possibilidades reais do emprego desta disciplina no âmbito do Corpo de Bombeiros Militar. Este estudo viabiliza, de imediato, a realização de benchmarking em torno das iniciativas compiladas, haja vista que a maior parte delas já é desenvolvida, na prática, pelas instituições adiante nomeadas.

Palavras-chave: Administração Pública. Gestão do Conhecimento. Aprendizagem organizacional. Corpo de Bombeiros. Organizações Militares.

\footnotetext{
1 Oficial do Corpo de Bombeiros Militar de Alagoas, Mestre em Administração Pública, Especialista em Pedagogia Estratégica e Gestão Educacional

2 Professor Adjunto da Universidade Federal de Alagoas, Doutor em Administração de Empresas e Mestre em Educação Brasileira
} 


\title{
KNOWLEDGE MANAGEMENT: CONTRIBUTIONS AND POSSIBILITIES FOR THE MILITARY FIRE SERVICE
}

\begin{abstract}
Knowledge is a valuable asset for organizations and, as such, must be properly managed. In this perspective, Knowledge Management presents itself as a viable alternative for optimizing the performance of public and private organizations, as it guarantees the use of intellectual capital in a systematic and planned way. This study aimed to clarify the benefits and applicability of Knowledge Management to the Military Fire Service. To this end, mediated by bibliographic and documentary research, different Knowledge Management initiatives, formally recognized, were explored in organizations in the areas of defense and public security, in Brazil and abroad. As a result, 7 international and 12 national cases were mapped, the examination of which allowed the identification of real possibilities for the use of this discipline within the scope of the Military Fire Service. This study immediately enables benchmarking around the initiatives compiled, given that most of them are already developed, in practice, by the institutions named below.
\end{abstract}

Keywords: Public administration. Knowledge management. Organizational learning. Fire Service. Military Organizations.

Artigo Recebido em 13/08/2020 e Aceito em 20/10/2020

\section{INTRODUÇÃO}

O Corpo de Bombeiros Militar (CBM) é uma organização intensiva em conhecimentos, condição que resulta do seu vasto rol de atuação operacional e complexa estrutura administrativa. Parte significativa do potencial deste conhecimento pode estar sendo desperdiçada pela inexistência de uma estratégia deliberada de gestão deste importante ativo organizacional.

Neste viés, a Gestão do Conhecimento (GC) se apresenta como alternativa viável para a otimização do desempenho de organizações públicas 


\section{Revista FLAMMAE}

Revista Científica do Corpo de Bombeiros Militar de Pernambuco

Artigo Publicado no Vol.06 N.17 - Edição Jul a Dez 2020 - ISSN 2359-4829

Versão on-line disponível em: http://www.revistaflammae.com

ou privadas (MCADAM; REID, 2000), à medida que se propõe à coordenação do pessoal, da tecnologia, dos processos e da estrutura organizacional necessária para a criação, o compartilhamento e a aplicação do conhecimento, a fim de promover a aprendizagem contínua na organização (DALKIR, 2005).

Dentre os diversos benefícios da GC para o setor público, salientam-se os seguintes, reconhecidos pela Organização para a Cooperação e Desenvolvimento Econômico (OCDE): minimiza a duplicação de esforços; repara a perda de conhecimentos e promove a aprendizagem continuada; aumenta a eficiência pela produção e compartilhamento de conhecimentos; integra o conhecimento do ambiente interno e externo (OCDE, 2003).

Para Massaro, Dumay e Garlatti (2015), a despeito da elevada importância do conhecimento em áreas essenciais, como nas forças armadas, polícia, corpo de bombeiros e serviços de emergências, há poucos estudos de GC em torno desse rol de instituições. Tal apontamento se reforça pela criticidade do conhecimento na atividade finalística destas organizações, onde um erro eventual poderá repercutir num custo imensurável, resultando, em último nível, na perda de uma vida humana.

Neste sentido, o presente trabalho teve por objetivo esclarecer os benefícios e a aplicabilidade da Gestão do Conhecimento para o Corpo de Bombeiros Militar. Para tanto, mediada pela pesquisa bibliográfica e documental, foram exploradas diferentes iniciativas de GC, formalmente reconhecidas, em organizações de natureza similar ao CBM, nas áreas de defesa e segurança pública, no Brasil e no exterior.

Para além desta introdução, integram este artigo um referencial teórico, apresentado a seguir, sendo sucedido, então, pelas considerações metodológicas. Em seguida, dá-se a análise e discussão dos resultados, tendo seu fechamento realizado pela conclusão.

\section{REFERENCIAL TEÓRICO}

2.1 Gestão do Conhecimento: conceito, práticas e ferramentas 
Na visão de Grant (2013), o conhecimento é um recurso intangível e pode ser combinado com outros ativos da organização, a exemplo dos recursos físicos e financeiros, para criar capacidades e agregar valor. Por outro lado, o conhecimento inadequado pode acarretar em mudanças frequentes, em erros e no retrabalho (YAP et al., 2017). Neste viés, torna-se necessária a adoção de uma metodologia que, de maneira sistemática, seja capaz de manejar este conhecimento, agregando valor às pessoas, equipes e organizações. Para Dalkir (2005), disto se encarrega a GC, campo multidisciplinar do saber, que, em linhas gerais, obedece à seguinte definição:

\begin{abstract}
A Gestão do Conhecimento representa uma abordagem deliberada e sistemática para garantir a plena utilização da base de conhecimento da organização, juntamente com o potencial de habilidades, competências, pensamentos, inovações e ideias individuais, para criar uma organização mais eficiente e eficaz (DALKIR, 2005: p. 2).
\end{abstract}

Os objetivos da GC são resumidos por Strauhs et al. (2012) como os seguintes: I) Aprendizado; II) Desenvolvimento de competências; e III) Mapeamento, codificação e compartilhamento do conhecimento organizacional. No que diz respeito ao aprendizado, pode ser obtido pelo estudo dos sucessos ou das falhas de indivíduos e equipes, ou mesmo das lições oriundas do ambiente externo à organização; o desenvolvimento de competências é o conjunto de conhecimentos, habilidades e atitudes necessárias ao bom desempenho das atividades laborais, que devem ser reconhecidas e direcionadas para o benefício do indivíduo e da organização; por fim, o conhecimento dos colaboradores deve ser identificado e mapeado, formando uma espécie de matriz para consulta de todos na organização (STRAUHS et al., 2012).

Para além da diversidade de conceitos, modelos e definições teóricas, há de se salientar que a GC se manifesta por meio de um portfólio de práticas e ferramentas, que deve ser antecipadamente planejado e alinhado à estratégia da organização, sob os cuidados de uma estrutura de governança apropriada. Segundo Heisig (2016), na falta de uma estratégia de GC, norteada por objetivos claros e apoiada por recursos adequados, as iniciativas soltas 
Revista Científica do Corpo de Bombeiros Militar de Pernambuco

Artigo Publicado no Vol.06 N.17 - Edição Jul a Dez 2020 - ISSN 2359-4829

Versão on-line disponível em: http://www.revistaflammae.com

dificilmente serão integradas e coordenadas em meio às diferentes unidades e departamentos de uma organização.

Dentre as inúmeras práticas, ferramentas e tecnologias, que tem por objetivo operacionalizar a estratégia de GC da organização, o Quadro 1 sumariza as principais iniciativas que podem integrar o kit personalizado de GC das corporações:

Quadro 1 - Principais práticas e ferramentas de GC.

\begin{tabular}{|c|c|c|}
\hline Denominação & Descrição & Referência \\
\hline $\begin{array}{l}\text { Lições } \\
\text { Aprendidas ou } \\
\text { Revisão Pós- } \\
\text { Acão }\end{array}$ & $\begin{array}{c}\text { Relatos de experiências em que se registra o que } \\
\text { aconteceu, o que se esperava que acontecesse e o } \\
\text { que foi aprendido durante este processo. }\end{array}$ & \multirow{5}{*}{ (BATISTA, 2012) } \\
\hline Melhores Práticas & $\begin{array}{c}\text { Procedimento validado para a realização de uma } \\
\text { tarefa ou solução de um problema, documentadas } \\
\text { por meio de bancos de dados, manuais ou } \\
\text { diretrizes. }\end{array}$ & \\
\hline Benchmarking & $\begin{array}{c}\text { É a busca das melhores referências em termos de } \\
\text { processo, produto ou serviço, para fins de } \\
\text { comparação. }\end{array}$ & \\
\hline $\begin{array}{c}\text { Banco de } \\
\text { Competências }\end{array}$ & $\begin{array}{l}\text { É um repositório que aponta as pessoas ou } \\
\text { equipes detentoras de determinado conhecimento. }\end{array}$ & \\
\hline $\begin{array}{c}\text { Banco de } \\
\text { Talentos ou } \\
\text { Páginas Amarelas }\end{array}$ & $\begin{array}{l}\text { Detalha as capacidades profissionais ao nível do } \\
\text { indivíduo, evidenciando sua expertise, experiência } \\
\text { e habilidades pessoais. }\end{array}$ & \\
\hline $\begin{array}{l}\text { Narrativas ou } \\
\text { Storytelling }\end{array}$ & $\begin{array}{l}\text { Utiliza-se do potencial das histórias organizacionais } \\
\text { para o compartilhamento de conhecimento, valores } \\
\text { e tradições. }\end{array}$ & $\begin{array}{l}\text { (DAVENPORT; } \\
\text { PRUSSAK, 2003; } \\
\text { STRAUHS et al., } \\
\text { 2012; SWAP et al., } \\
\text { 2001) }\end{array}$ \\
\hline $\begin{array}{l}\text { Comunidades de } \\
\text { Prática }\end{array}$ & $\begin{array}{c}\text { Grupos de pessoas que compartilham um interesse } \\
\text { em comum e se engajam em um processo de } \\
\text { aprendizagem coletiva. }\end{array}$ & $\begin{array}{c}\text { (WENGER; } \\
\text { WENGER- } \\
\text { TRAYNER, 2015) }\end{array}$ \\
\hline $\begin{array}{l}\text { Educação } \\
\text { Corporativa }\end{array}$ & $\begin{array}{c}\text { Tem por objetivo o desenvolvimento de pessoas } \\
\text { através de medidas de capacitação continuada em } \\
\text { todas as áreas da organização. }\end{array}$ & $\begin{array}{l}\text { (SCHLESINGER et } \\
\text { al., 2008; } \\
\text { BATISTA, 2012) }\end{array}$ \\
\hline $\begin{array}{c}\text { Portal } \\
\text { Corporativo }\end{array}$ & $\begin{array}{c}\text { Ambiente virtual que organiza e facilita o acesso ao } \\
\text { conhecimento organizacional, além de possibilitar a } \\
\text { interação e colaboração entre as pessoas. }\end{array}$ & $\begin{array}{l}\text { (SCHLESINGER et } \\
\text { al., 2008; LAPA; } \\
\text { RODRÍGUEZ, } \\
\text { 2016) }\end{array}$ \\
\hline $\begin{array}{l}\text { Inteligência } \\
\text { Organizacional }\end{array}$ & $\begin{array}{l}\text { Transforma dados em conhecimento útil para a } \\
\text { organização, sob o suporte de tecnologias } \\
\text { adequadas, colaborando para a tomada de decisão } \\
\text { inteligente. }\end{array}$ & $\begin{array}{l}\text { (CODY et al., } \\
\text { 2002) }\end{array}$ \\
\hline
\end{tabular}

Fonte: Elaborado pelo autor.

Feitas as considerações iniciais sobre a GC, necessário se faz reconhecer o potencial desta disciplina para a otimização do serviço público em 


\section{Revista FLAMMAE}

Revista Científica do Corpo de Bombeiros Militar de Pernambuco

Artigo Publicado no Vol.06 N.17 - Edição Jul a Dez 2020 - ISSN 2359-4829

Versão on-line disponível em: http://www.revistaflammae.com

geral, para que, adiante, seja melhor compreendida sua aplicabilidade para os Corpos de Bombeiros Militares e outras instituições de natureza similar, sobretudo nas áreas de defesa e segurança pública.

\subsection{Gestão do Conhecimento na Administração Pública}

Para Schlesinger et al. (2008) e Angelis (2011), as transformações sociais e econômicas se refletem na administração pública, exigindo-lhe uma maior capacidade de adaptação e resolução de problemas. Por outro lado, à medida que se tornam conscientes de seus direitos e deveres, os cidadãos estão cada vez mais exigentes por serviços públicos de qualidade, sinalizando para a necessidade de melhorias na maneira atual de gerir a coisa pública, tendo o conhecimento um papel fundamental neste processo (SCHLESINGER et al., 2008).

A aplicação da GC no setor público, para Agune et al. (2014), está diretamente relacionada ao aumento da sua capacidade de inovação, contribuindo, dessa forma, para o enfrentamento dos inúmeros desafios deste segmento. Para tanto, na visão dos autores, várias são as medidas que devem ser tomadas para a adequação das instituições aos preceitos da GC, dentre as quais: a adoção de programas de capacitação, que ensejem na formação de uma cultura inovadora, com novas disciplinas e metodologias que privilegiem a inovação; a redefinição do papel do gestor público, com foco na inovação; o protagonismo das pessoas na organização inovadora; o aproveitamento do potencial das plataformas sociais para fins de GC; a existência de rotinas e processos organizados e a gestão de desempenho, por meio de metas e indicadores; por fim, o estímulo ao trabalho colaborativo e à cultura de participação, primeiramente, no ambiente interno da organização, estendendose para a comunidade local e à sociedade como um todo (AGUNE et al., 2014).

Para além do aumento na capacidade de inovação, há diversas potencialidades da GC para o setor público, tais como: auxilia na formulação da estratégia das organizações (TAKEUCHI, 2013); evita a repetição de erros (DALKIR, 2005); otimiza a tomada de decisão (ANGELIS, 2014); promove a 


\section{Revista FLAMMAE}

Revista Científica do Corpo de Bombeiros Militar de Pernambuco

Artigo Publicado no Vol.06 N.17 - Edição Jul a Dez 2020 - ISSN 2359-4829

Versão on-line disponível em: http://www.revistaflammae.com

melhoria dos processos internos e das competências essenciais da organização, além de aumentar a eficiência, a qualidade e a efetividade social dos serviços prestados à população (BATISTA, 2012).

Por outro lado, há de se ressaltar a existência de entraves recorrentes à implementação da GC no setor público, dentre eles: a cultura organizacional, que implica na resistência à mudanças e no acúmulo de conhecimento, ao invés do compartilhamento (SVEIBY; SIMONS, 2002); o tamanho das organizações públicas, que dificulta a adoção de mudanças abrangentes (COELHO, 2004); a natureza burocrática e hierárquica das organizações (ANGELIS, 2015); e a baixa divulgação das estratégias de GC (OCDE, 2003).

Esclarecidas potencialidades e características da Gestão do Conhecimento para o setor público, passa-se às considerações metodológicas em torno do presente estudo, facilitando a compreensão dos resultados que se seguem.

\section{METODOLOGIA}

Na condição de um estudo exploratório, busca-se uma aproximação com a GC enquanto fenômeno pesquisado, visualizando-a de uma forma aplicada à realidade dos CBM e de organizações de natureza similar. À medida que se visa uma maior compreensão do tema, em resposta ao lócus de pesquisa apontado por Massaro, Dumay e Garlatti (2015), transcrito na introdução, optase pela abordagem qualitativa, manifestada pela interpretação reflexiva dos dados, sem viés de quantificação.

No que diz respeito às técnicas de coleta, prima-se pela pesquisa bibliográfica, tomando por base o exame de artigos científicos, livros e manuais acadêmicos, com o fito de se reunirem achados em torno do objeto de estudo: a GC aplicada ao CBM. Em complemento, a pesquisa documental colabora na procura por casos práticos que não foram registrados em produções científicas, recorrendo-se à fontes oficiais, acessadas por meio de ambientes digitais.

Como plataformas de pesquisa, recorreu-se ao Scopus, Periódicos CAPES e Google Acadêmico. Dentre os scripts de busca mais utilizados, 
Revista Científica do Corpo de Bombeiros Militar de Pernambuco

Artigo Publicado no Vol.06 N.17 - Edição Jul a Dez 2020 - ISSN 2359-4829

Versão on-line disponível em: http://www.revistaflammae.com

estão: "gestão do conhecimento" e "setor público" ou "administração pública"; "gestão do conhecimento" e "organizações militares" ou "forças armadas"; "gestão do conhecimento" e "exército" ou "marinha" ou "aeronáutica" ou "polícia" ou "corpo de bombeiros". Foram utilizados os correspondentes destes termos no idioma inglês, sendo a busca normalmente realizada junto ao título, resumo e palavras-chave das publicações. Para além das plataformas supracitadas, recorreu-se ao buscador Google, haja vista que uma parte dos casos aqui relatados não teve sua experiência publicada em bases acadêmicas.

Como critérios de inclusão, foram consideradas as publicações (acadêmicas e não acadêmicas) que registram casos correlatos de GC em corporações de bombeiros, instituições militares e órgãos de segurança pública do Brasil e do exterior, culminando no mapeamento de 7 casos internacionais e 12 nacionais, que passam a ser analisados e discutidos adiante.

\section{RESULTADOS}

\subsection{Casos correlatos no exterior}

\subsubsection{US Army (Exército dos Estados Unidos)}

No Exército dos Estados Unidos (US Army), segundo Lausin, De Souza e Kraft (2003), a Gestão do Conhecimento não é um fenômeno tão novo quanto se imagina; na verdade, é uma atividade básica, tão antiga quanto a própria instituição, sendo desenvolvida por séculos, tendo por fonte primária o conhecimento tácito dos seus militares, que se difunde através do treinamento contínuo. Para os autores, as iniciativas de GC desta organização militar são dignas do reconhecimento tanto do setor público quanto do setor privado, sendo o componente tecnológico apenas um agente facilitador, à medida que a aprendizagem e o compartilhamento de conhecimento ocorrem de maneira intrínseca na instituição. 
Revista Científica do Corpo de Bombeiros Militar de Pernambuco

Artigo Publicado no Vol.06 N.17 - Edição Jul a Dez 2020 - ISSN 2359-4829

Versão on-line disponível em: http://www.revistaflammae.com

Ainda na visão de Lausin, De Souza e Kraft (2003), a definição clara de objetivos nas ações, a padronização de procedimentos e a disseminação de uma doutrina institucional, encabeçada pelo US Army Training and Doctrine Command (TRADOC), caracterizam o modus operandi da GC no exército norte-americano. Dentre as principais iniciativas de GC adotadas nesta instituição, destaca-se a utilização de Lições Aprendidas (AAR), conduzida pela unidade denominada Center for Army Lessons Learned (CALL), apontada por Davenport e Prusak (2003) como um caso de sucesso no emprego deste tipo de prática. Aplicado em treinamentos e missões reais, os resultados do AAR são rapidamente incorporados na doutrina do exército, ou em seus procedimentos formalmente documentados, e nos programas de treinamento (DAVENPORT; PRUSAK, 2003: p. 7).

Como ferramenta tecnológica de GC desta corporação, cabe mencionar, ainda, o portal US Army Knowledge Online (AKO), que permite o compartilhamento de conhecimento entre os integrantes do exército alocados por todo o globo, colaborando para o objetivo institucional de se consolidar como uma organização baseada no conhecimento (LAUSIN; DE SOUZA; KRAFT, 2003).

\subsubsection{Australian Army (Exército australiano)}

A estratégia de GC do Exército Australiano, explorada por McDowall, Rynne e Talbot (2014), é desenvolvida sobre uma sólida base teórica, tendo o conhecimento um papel importante para o aprimoramento das ações de treinamento e educação corporativa. Prova disso é que a última versão do Manual de Doutrina de Guerra Terrestre 7-0 (Treinamento e Educação) deixa claro o protagonismo da aprendizagem organizacional para a instituição, destacando o papel das seguintes práticas de GC: revisão pós-ação, relatórios pós-atividade, lições aprendidas e repositório de conhecimentos, que possibilitam a captura e o compartilhamento de conhecimentos adquiridos em operações e treinamentos (THE AUSTRALIAN ARMY, 2018).

\subsubsection{UK Police (Polícia do Reino Unido)}


Revista Científica do Corpo de Bombeiros Militar de Pernambuco

Artigo Publicado no Vol.06 N.17 - Edição Jul a Dez 2020 - ISSN 2359-4829

Versão on-line disponível em: http://www.revistaflammae.com

$\mathrm{Na}$ área policial, há achados relevantes em torno do desenvolvimento da GC em organizações desta natureza. Seba e Rowley (2010) realizaram um estudo de casos múltiplos em quatro instituições policiais do Reino Unido, constatando que em nenhuma delas existe uma estratégia deliberada e abrangente de GC, apesar de reconhecerem a existência de algumas iniciativas nesta área para o aumento da efetividade das forças policiais britânicas. São apontadas, ainda, barreiras culturais ao compartilhamento de conhecimento nas corporações, onde se relata a ideia de que "conhecimento é poder" (SEBA; ROWLEY, 2010).

\subsubsection{Dubai Police (Polícia de Dubai)}

Em um segundo estudo, Seba, Rowley e Delbridge (2012) constatam que, na polícia de Dubai, nos Emirados Árabes Unidos, reconhecida pelo pensamento progressivo e a inovação, há um comprometimento estratégico em torno do emprego da GC para o aumento da performance organizacional, onde se dispõe, inclusive, de um departamento específico para tal. Mesmo assim, foram identificados entraves à consolidação de uma cultura de conhecimento na instituição, sendo estes relacionados à estrutura organizacional, à liderança, à alocação de tempo, e à confiança (SEBA; ROWLEY; DELBRIDGE, 2012).

4.1.5 New South Wales Fire Brigades (Corpo de Bombeiros de New South Wales)

No âmbito do Corpo de Bombeiros, Pickles (2004) propôs uma infraestrutura tecnológica de GC para a corporação de New South Wales, na Austrália, objetivando o desenvolvimento de uma cultura de GC na organização. Sua proposta se baseia numa plataforma a ser implementada junto à intranet da instituição, dando suporte à adoção de iniciativas como o compartilhamento de histórias (Storytelling), o envio de relatórios pós-missão e a criação de comunidades de prática virtuais, otimizando, assim, o fluxo da informação e do conhecimento na instituição (PICKLES, 2004). 


\section{Revista FLAMMAE}

Revista Científica do Corpo de Bombeiros Militar de Pernambuco

Artigo Publicado no Vol.06 N.17 - Edição Jul a Dez 2020 - ISSN 2359-4829

Versão on-line disponível em: http://www.revistaflammae.com

4.1.6 Illinois Fire Service Institute (Instituto de Bombeiros de Illinois)

Em Illinois, nos Estados Unidos, o serviço de bombeiros é objeto do trabalho de Ruan e Groves (2013), que tem como produto uma iniciativa de GC que propõe um banco de dados de bombeiros que morreram no cumprimento do dever. A ferramenta é composta por registros, informações e imagens do profissional e do incidente que levou a sua morte em serviço, contribuindo para a manutenção de uma memória organizacional em torno deste tipo de evento. Para além da homenagem póstuma conferida aos falecidos, trata-se de um repositório valioso para fins de treinamento, educação e pesquisa, haja vista que possibilita a aprendizagem em torno de casos reais, prevenindo novos acontecimentos (RUAN; GROVES, 2013).

4.1.7 Australian Institute for Disaster Resilience (Instituto australiano para resiliência a desastres)

Sob a gestão do Australian Institute for Disaster Resilience (AIDR), uma instituição que se dedica ao desenvolvimento, manutenção e compartilhamento de conhecimento para apoiar a resiliência da comunidade australiana na ocorrência de desastres (AIDR, 2020), nota-se, em meio ao seu portfólio de ações, a aplicabilidade da $\mathrm{GC}$ em várias iniciativas voltadas à Proteção e Defesa Civil. O trabalho integrado entre os setores público e privado, ONGs, instituições de pesquisa e a comunidade resulta num vasto rol de práticas direcionadas à prevenção e minimização dos efeitos dos desastres, desde o portal do conhecimento até programas educacionais, eventos, periódicos científicos e uma coleção de manuais (AIDR, 2020). Um desses manuais se dedica à gestão de lições aprendidas, que prima pelo aprimoramento contínuo, evitando a repetição de erros e replicando fatores de sucesso, em consonância ao ideal de aprendizagem organizacional (AIDR, 2013).

\subsection{Casos correlatos no Brasil}

No Brasil, há também registros do emprego da GC em órgãos de segurança pública e defesa nacional, de onde se extraem apontamentos 


\section{Revista FLAMMAE}

Revista Científica do Corpo de Bombeiros Militar de Pernambuco

Artigo Publicado no Vol.06 N.17 - Edição Jul a Dez 2020 - ISSN 2359-4829

Versão on-line disponível em: http://www.revistaflammae.com

importantes para a consecução dos objetivos da pesquisa, haja vista as semelhanças estruturais e finalísticas com a instituição alvo deste estudo, o Corpo de Bombeiros Militar.

\subsubsection{Exército Brasileiro (EB)}

Iniciando pelas forças armadas, o caso do Exército Brasileiro evidencia esforços em torno do emprego da GC para o desenvolvimento institucional, sobretudo no que tange à Doutrina Militar Terrestre, o conjunto de valores, fundamentos, conceitos, concepções, táticas, técnicas, normas e procedimentos que tem por finalidade orientar a força no preparo de seus meios para a atividade fim (EB, 2017).

No trabalho de Jansen (2013), é apresentada uma nova estrutura para a produção doutrinária no EB, como alternativa à solução de alguns problemas por ele pontuados, tais como: a falta de um canal técnico para o compartilhamento de conhecimento; a falta de um banco de dados de doutrina e de uma rotina de coleta e utilização de lições aprendidas; o baixo aproveitamento da experiência de militares em cursos e missões no exterior; a falta de um cadastro de especialistas; além de dificuldades culturais na gestão de pessoas por competências. Neste sentido, o autor sinaliza à incorporação de melhorias pelo advento do Sistema de Doutrina Militar Terrestre (SIDOMT), ilustrado na Figura 1, uma estrutura em rede sob a governança de um órgão central: o Centro de Doutrina do Exército (C Dout Ex).

Paralelamente, foram criadas Seções de Doutrina e Lições Aprendidas nos diversos setores e comandos militares. Primou-se, ainda, pela ampliação da produção de conhecimento com a implantação do Portal de Doutrina e do periódico Doutrina Militar em Revista (JANSEN, 2013). Destaca-se ainda, segundo Jansen (2013), a importância das atividades de pesquisa, simulação e experimentação como base para a geração de novos conhecimentos. 
Figura 1 - Estrutura do SIDOMT do Exército Brasileiro

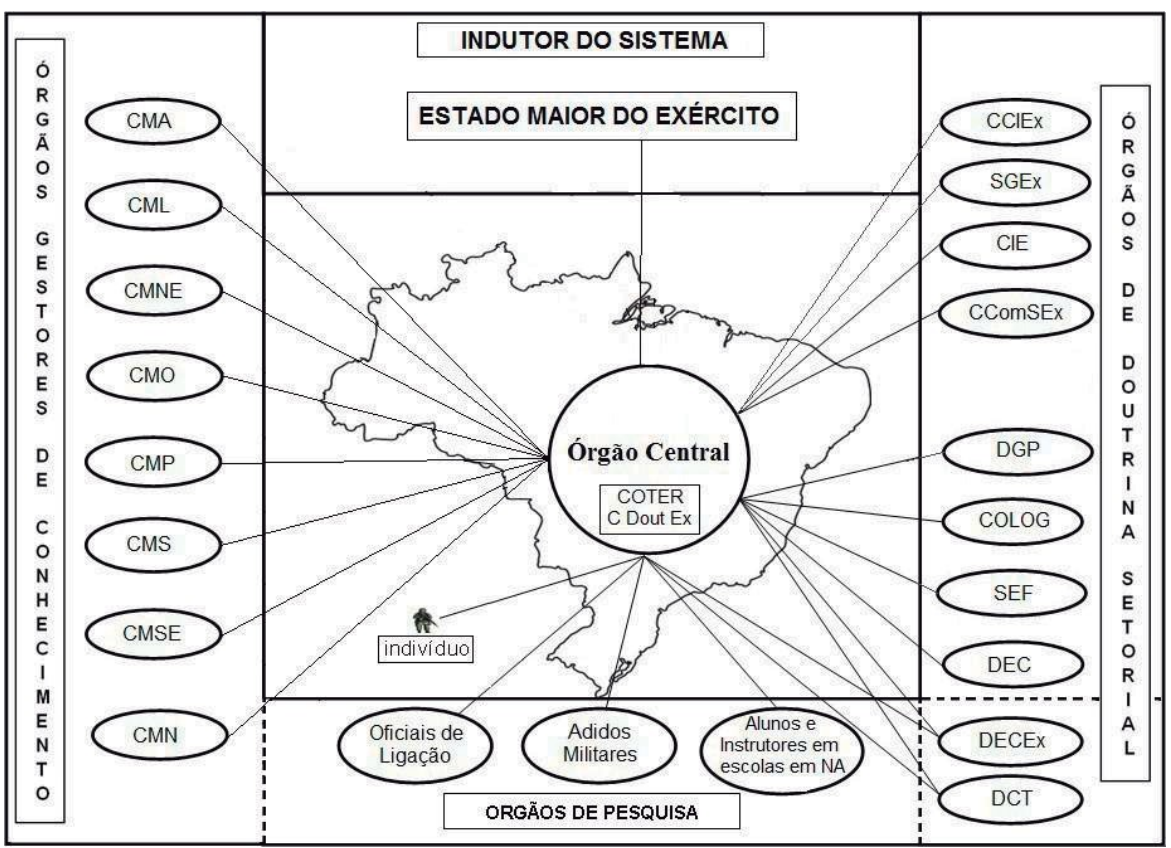

Fonte: Exército Brasileiro (2017).

Para Betat (2017), os avanços obtidos no aprendizado organizacional do EB, pela via da Gestão do Conhecimento Doutrinário (GCD), vieram por meio de práticas como: Sistemática de Acompanhamento Doutrinário e Lições Aprendidas (SADLA); Biblioteca Digital; fóruns de discussão; participação em eventos e intercâmbios (Atv Esp); análise e validação de trabalhos de natureza profissional (TNP).

Atualmente, as Instruções Reguladoras da GCD esclarecem o papel e o funcionamento das fontes de conhecimento doutrinário (FCD), representado na Figura 2, colaborando para a formação de uma doutrina consistente e inovadora (EB, 2015). 
Revista Científica do Corpo de Bombeiros Militar de Pernambuco

Artigo Publicado no Vol.06 N.17 - Edição Jul a Dez 2020 - ISSN 2359-4829

Versão on-line disponível em: http://www.revistaflammae.com

Figura 2 - Integração das FCD e a obtenção de produtos doutrinários

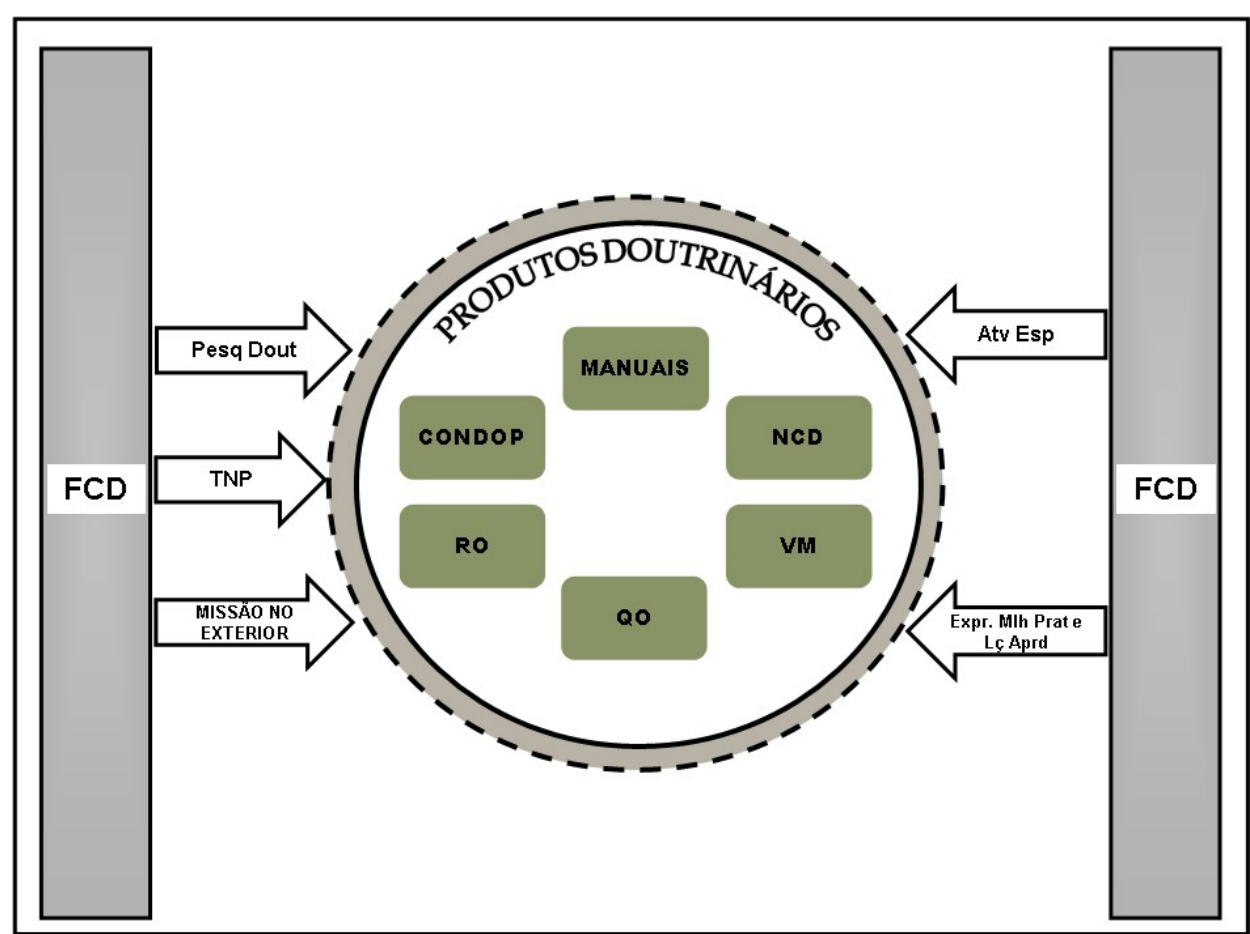

Fonte: Exército Brasileiro (2015).

4.2.2 Corpo de Fuzileiros Navais da Marinha do Brasil (CFN)

Na Marinha do Brasil, o Sistema de Gestão de Conhecimento dos Fuzileiros Navais (SGC-FN), gerido pelo Comando do Desenvolvimento Doutrinário do Corpo de Fuzileiros Navais (CDDCFN), representa o engajamento institucional com a GC. Para Almeida e Ferreira (2015), apesar da existência de uma vasta fonte de conhecimentos na corporação, não havia uma sistematização prévia à implementação do SGC-FN, o qual se propôs a gerir de maneira adequada este capital intangível, estruturando-se de acordo com a Figura 3: 


\section{Revista FLAMMAE}

Revista Científica do Corpo de Bombeiros Militar de Pernambuco

Artigo Publicado no Vol.06 N.17 - Edição Jul a Dez 2020 - ISSN 2359-4829

Versão on-line disponível em: http://www.revistaflammae.com

Figura 3 - Estrutura do Sistema de GC dos Fuzileiros Navais

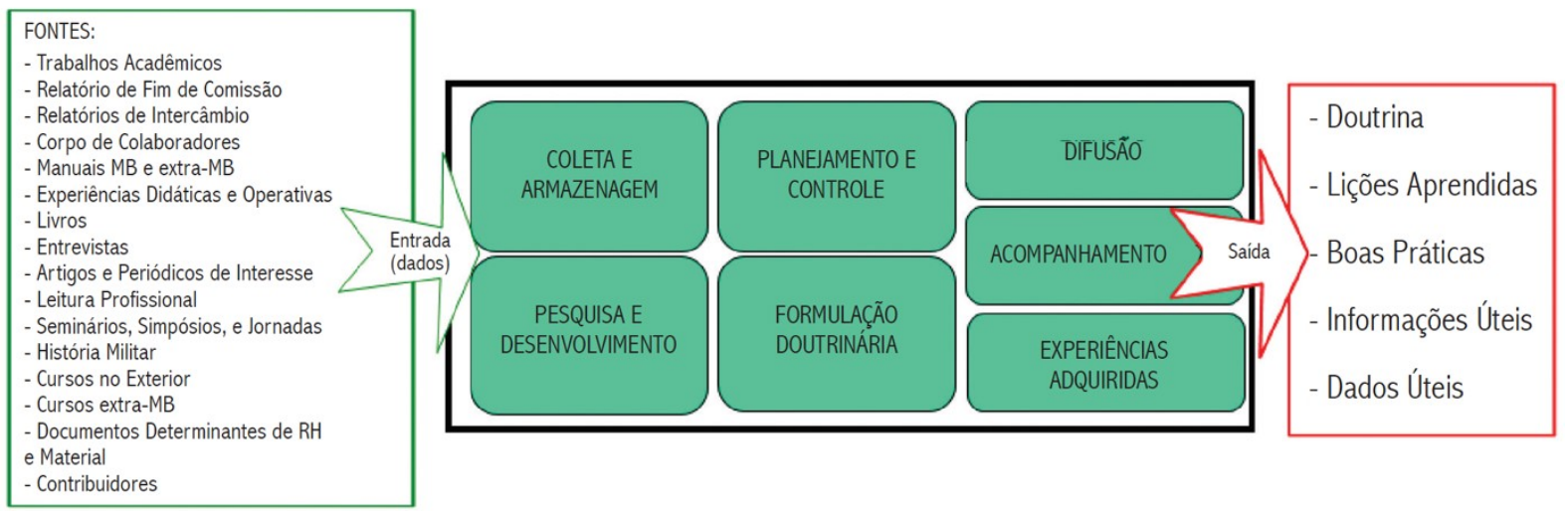

Fonte: Almeida e Ferreira (2015).

Dentre as práticas que coadunam para os ganhos obtidos com a implantação do SGC-FN, podem ser relatadas: o Corpo de Colaboradores, que busca representar os setores do CFN para a produção doutrinaria, munindo-a de conhecimento tácito; o Portal do Conhecimento, que possibilita o acesso aos diversos produtos de conhecimento explícito do SGC-FN; o Programa de Leitura Profissional, que visa o aprimoramento de competências pelo estímulo à leitura profissional; o Grupo de Observação e Assessoramento Doutrinário, que acompanha o desenvolvimento de exercícios de adestramento; além do periódico Âncoras e Fuzis e a tradicional série de manuais da corporação (ALMEIDA; FERREIRA, 2015).

\subsubsection{Força Aérea Brasileira (FAB)}

Na Força Aérea Brasileira, apesar de não serem constatados trabalhos acadêmicos sobre a questão, nota-se, em seu organograma, a existência de uma Divisão de Gestão de Conhecimento (DIVGC) subordinada ao Instituto de Aplicações Operacionais (IAOP), o qual se encarrega do suporte técnicocientífico necessário ao preparo e emprego operacional da força (FAB, 2015). 
4.2.4 Polícia Militar de Minas Gerais (PMMG)

Adentrando na área de segurança pública, no âmbito da Polícia Militar (PM), há também registros do envolvimento institucional com o tema da GC em alguns estados da federação. O trabalho de Batista et al. (2015) traz o caso da Polícia Militar de Minas Gerais, cujo processo de implantação da GC funcionou como uma espécie de piloto para o governo estadual. Sob a coordenação do Núcleo de Gestão do Conhecimento, subordinado à Assessoria de Desenvolvimento Organizacional, propôs-se a criação de um comitê de GC na instituição, composto por representantes dos seus diversos setores, que se envolveu num trabalho estruturado em cinco etapas: 1) Diagnóstico de Maturidade; 2) Workshop de conhecimento teórico do modelo; 3) Workshop de aplicação do modelo; 4) Validação dos pré-projetos; 5) Elaboração e execução dos projetos (BATISTA et al., 2015).

\subsubsection{Polícia Militar de Santa Catarina (PMSC)}

Em Santa Catarina, Silveira (2013) propôs diretrizes para a implementação da GC no Centro de Ensino da Polícia Militar, de maneira a amenizar as fragilidades constatadas em um diagnóstico realizado junto à equipe de gestores do setor, dentre elas: desconhecimento e baixo envolvimento dos dirigentes com as práticas de GC; poucas ações de pesquisa em GC; falta de práticas de monitoramento e compartilhamento dos conhecimentos produzidos nas atividades de ensino, pesquisa e extensão da PM; e o baixo controle da propriedade intelectual.

\subsubsection{Polícia Militar do Estado de São Paulo (PMESP)}

Já em São Paulo, a Polícia Militar registra, no seu Plano de Comando 2018-2019, a intenção de "aperfeiçoar o uso dos mecanismos de Gestão do Conhecimento" (PMESP, 2019) como seu objetivo estratégico $n^{\circ} 2$. 


\section{Revista FLAMMAE}

Revista Científica do Corpo de Bombeiros Militar de Pernambuco

Artigo Publicado no Vol.06 N.17 - Edição Jul a Dez 2020 - ISSN 2359-4829

Versão on-line disponível em: http://www.revistaflammae.com

Ainda no âmbito desta corporação, Souza, Trevisan e Siqueira (2019) analisam uma série de sistemas inteligentes da PMESP sob os preceitos da GC, os quais são diretamente utilizados para otimizar o cumprimento da missão institucional.

\subsubsection{Corpo de Bombeiros Militar de Alagoas (CBMAL)}

No Corpo de Bombeiros Militar, alguns trabalhos denotam a crescente importância do tema no âmbito das corporações. No estado de Alagoas, em um estudo de caso realizado em torno da experiência das comunidades de prática do Corpo de Bombeiros Militar, Lira e Lemos (2017) afirmaram se tratar de uma iniciativa isolada na área de GC, dentre outras possivelmente existentes, que deveriam ser inventariadas e integradas em um Plano de Gestão do Conhecimento (PGC), alinhado à estratégia da instituição. Por sua vez, ao explorarem as perspectivas do tema para a corporação, Lira e Pinto (2018) ratificaram tal constatação, percebendo uma realidade que pouco diverge da maior parte das organizações públicas do Brasil em termos de GC: apesar da existência de práticas esporádicas, a falta de institucionalização é um entrave para o aproveitamento pleno das potencialidades da GC, cujos resultados são diretamente relacionados ao grau de formalização estratégica da questão (BATISTA, 2015).

Em consequência, Lira (2019) apresenta uma proposta de intervenção que tem por objetivo a institucionalização da GC nesta corporação. Baseado no diagnóstico organizacional de GC, o autor estabelece um conjunto de recomendações técnico-científicas e um plano de ação que assessoram a implementação das medidas necessárias ao processo de institucionalização da GC. Como resultado, "desenvolver a doutrina operacional e gestão do conhecimento" é um dos objetivos estratégicos do CBMAL para o período de 2020-2024, por meio de diversas iniciativas (CBMAL, 2020). 


\section{Revista FLAMMAE}

Revista Científica do Corpo de Bombeiros Militar de Pernambuco

Artigo Publicado no Vol.06 N.17 - Edição Jul a Dez 2020 - ISSN 2359-4829

Versão on-line disponível em: http://www.revistaflammae.com

4.2.8 Corpo de Bombeiros Militar do Distrito Federal (CBMDF)

No Distrito Federal, visando a estruturação da GC na corporação, Silva (2013) apresenta uma proposta de práticas adequadas à realidade da organização, como o aprimoramento do portal corporativo - através da inclusão de ferramentas como fóruns, chat rooms e groupware - além da implantação do ensino à distância e de comunidades de prática.

Em atenção ao tema, o Corpo de Bombeiros Militar do Distrito Federal (CBMDF), na última versão de seu Plano Estratégico, prevê o desenvolvimento da pesquisa e da Gestão do Conhecimento como um dos objetivos estratégicos da instituição para o período de 2017-2024. Para tanto, estabelece como iniciativas a realização de pesquisas, a oferta de cursos de mestrado e doutorado, a realização de eventos técnico-científicos, a retroalimentação dos ciclos operacionais, além da implementação do modelo de GC na corporação (CBMDF, 2016).

\subsubsection{Corpo de Bombeiros Militar do Espírito Santo (CBMES)}

No Espírito Santo, a corporação dispõe de uma unidade setorial encarregada da governança da GC. Trata-se do Departamento de Gestão do Conhecimento (DepGC), inserido na Assessoria Estratégica (AEST), que é subordinada diretamente ao Comandante Geral (CBMES, 2020). Dentre as iniciativas de GC, destacam-se os Comitês de Desenvolvimento de Atividades Bombeiro Militar (CDAs), uma espécie de Comunidades de Prática, sob gestão do DepGC, que tem por objetivo promover o desenvolvimento de áreas temáticas específicas daquela corporação (CBMES, 2017a). Além disso, o desenvolvimento da temática de GC vem sendo objeto de eventos específicos promovidos pela instituição (CBMES, 2017b)

\subsubsection{Corpo de Bombeiros Militar do Estado de Goiás (CBMGO)}

Em Goiás, Chaves (2015) traça uma reflexão acerca da aplicação da GC para o alcance dos objetivos estratégicos da organização. Seu estudo se 
Revista Científica do Corpo de Bombeiros Militar de Pernambuco

Artigo Publicado no Vol.06 N.17 - Edição Jul a Dez 2020 - ISSN 2359-4829

Versão on-line disponível em: http://www.revistaflammae.com

baseia na análise dos trabalhos científicos produzidos nos cursos da corporação, propondo sugestões para o seu melhor aproveitamento. Além disso, colabora com a proposição de uma estrutura de GC a ser formalizada na corporação, contemplando, para tanto, as seguintes ações: criação de um grupo de trabalho, de uma norma administrativa e de uma seção de GC; estabelecimento de parcerias; aperfeiçoamento do repositório digital; criação de um baú de ideias e um baú de histórias da corporação; realização de estudos de caso de ocorrências e procedimentos (CHAVES, 2015). Em decorrência do trabalho e do engajamento institucional, nota-se a implementação de algumas das medidas propostas, como a implementação do Portal do Conhecimento (CBMGO, 2019) que congrega várias modalidades de conhecimento explícito, além da criação de Grupos de Trabalho em várias áreas de especialidade (CBMGO, 2016).

\subsubsection{Corpo de Bombeiros Militar de Santa Catarina (CBMSC)}

Sarquis et al. (2016) apontam a existência de um rico contexto de aprendizagem organizacional no Corpo de Bombeiros Militar de Santa Catarina (CBMSC), que decorre de um programa de aprendizagem corporativa, da disseminação interna de informações, de reuniões de trabalho, da avaliação do desempenho pós-eventos/ocorrências e da avaliação do desempenho pessoal (SARQUIS et al., 2016: p. 1012).

Por sua vez, Acordi (2011) destaca o potencial de aprendizagem no CBMSC através da atividade de investigação de incêndios, que, segundo o autor, carece de uma gestão integrada que tome proveito das informações coletadas neste tipo de trabalho. Para tanto, propõe sugestões de melhoria desta atividade, contemplando as pessoas, infraestrutura e tecnologia.

\subsubsection{Defesa Civil}

Por fim, no âmbito da Defesa Civil, atribuição constitucional dos CBM, estudos endossam a aplicabilidade da Gestão do Conhecimento nesta área de atuação em particular. Em uma revisão teórica, Soriano, Hoffman e Araújo (2017) discutem a aplicabilidade dos conceitos de GC nos órgãos de Defesa 


\section{Revista FLAMMAE}

Revista Científica do Corpo de Bombeiros Militar de Pernambuco

Artigo Publicado no Vol.06 N.17 - Edição Jul a Dez 2020 - ISSN 2359-4829

Versão on-line disponível em: http://www.revistaflammae.com

Civil, identificando várias iniciativas com potencial de otimizar a gestão de desastres, tais como: revisão de ações realizadas; entrevistas de desligamento; comunidades de prática; gestão de conteúdo; melhores práticas; análise de redes sociais; páginas amarelas; e aprendizagem virtual. Da mesma forma, em um trabalho realizado em Santa Catarina por Cardoso et al. (2014), ratifica-se a importância da GC entre os profissionais envolvidos nas ações de resposta aos desastres naturais. Os autores enfatizam que, sob o uso de tecnologias adequadas e através da gestão do conhecimento tácito dos agentes públicos, espera-se o aumento de desempenho nas ações de apoio às vítimas e na minimização dos efeitos destas ocorrências (CARDOSO et al., 2014).

\section{CONCLUSÃO}

Mediado pela pesquisa bibliográfica e documental, o presente trabalho teve por objetivo esclarecer os benefícios e a aplicabilidade da Gestão do Conhecimento para o Corpo de Bombeiros Militar. Neste sentido, foram exploradas diferentes iniciativas de GC, formalmente reconhecidas, no âmbito do CBM e em organizações de natureza similar, nas áreas de defesa e segurança pública, no Brasil e no exterior.

No que diz respeito aos benefícios da GC, as considerações extraídas da literatura oferecem o suporte teórico necessário para compreensão deste tema de estudo, colaborando para o entendimento do seu potencial para a administração pública de maneira geral e, em especial, para o Corpo de Bombeiros Militar.

Quanto à aplicabilidade, o levantamento de casos correlatos, no Brasil e no exterior, permitiu a identificação de possibilidades reais do emprego da GC no Corpo de Bombeiros Militar, viabilizando, de imediato, a realização de benchmarking das iniciativas de GC compiladas no presente estudo, haja vista que a maior parte delas já é desenvolvida, na prática, por instituições de natureza similar. 


\section{Revista FLAMMAE}

Revista Científica do Corpo de Bombeiros Militar de Pernambuco

Artigo Publicado no Vol.06 N.17 - Edição Jul a Dez 2020 - ISSN 2359-4829

Versão on-line disponível em: http://www.revistaflammae.com

O mapeamento de casos e iniciativas de GC decorrente da pesquisa ratifica a importância do tema para os Corpos de Bombeiros. A Gestão do Conhecimento já faz parte da vanguarda Administração moderna, com vasto potencial para o setor público, e também sinaliza como tema de importância crescente no Brasil, em organizações da área de defesa e segurança pública.

Importante salientar que os resultados da GC são diretamente proporcionais ao seu grau de externalização e formalização junto às instituições. Ou seja, a exploração do seu pleno potencial deve estar atrelada aos direcionadores estratégicos da organização, norteada por um Plano de Gestão do Conhecimento e cuidada por uma estrutura de governança de GC bem estabelecida. Frisa-se, assim, que a adoção de práticas soltas, normalmente, apresenta resultados pontuais, esporádicos e limitados.

A contribuição acadêmica do presente estudo se atesta pela originalidade da abordagem conferida ao tema, com foco no Corpo de Bombeiros Militar, que poderá ser estendida às instituições de natureza similar, nas áreas de defesa e segurança pública do Brasil e do exterior. Para a sociedade, trás à tona uma oportunidade de melhoria dos serviços prestados pelas corporações, essenciais para a salvaguarda da vida, do patrimônio e do meio ambiente, garantidos pela constituição e imprescindíveis ao bem-estar social.

Como limitações da pesquisa, que poderá ser objeto da realização de trabalhos futuros, sugere-se a investigação em torno dos resultados obtidos, das dificuldades encontradas e da efetividade prática das iniciativas e casos de GC mapeados no presente estudo, ratificando, assim, a viabilidade e o potencial de cada um.

\section{REFERÊNCIAS}

ACORDI, Charles Fabiano. Gestão do Conhecimento em Organizações

Militares: um estudo de caso na atividade de investigação de incêndios. 2011. 177 f. Dissertação (Mestrado) - Curso de Mestrado em Administração, Universidade do Sul de Catarina, Florianópolis, 2011. 


\section{Revista FLAMMAE}

Revista Científica do Corpo de Bombeiros Militar de Pernambuco

Artigo Publicado no Vol.06 N.17 - Edição Jul a Dez 2020 - ISSN 2359-4829

Versão on-line disponível em: http://www.revistaflammae.com

AGUNE, Roberto et al. Gestão do Conhecimento e Inovação no Setor

Público: Dá pra fazer. São Paulo: Secretaria de Planejamento e

Desenvolvimento Regional, 2014. 167 p.

ALMEIDA, Nélio de; FERREIRA, Renato Rangel. O Sistema de Gestão do Conhecimento de Fuzileiros Navais. Âncoras e Fuzis: Corpo de Fuzileiros Navais, Mangaratiba, v. 14, n. 46, p.9-16, ago. 2015.

ANGELIS, Cristiano Trindade de. Gestão do Conhecimento no setor público: um estudo de caso por meio do método OKA. Revista do Serviço

Público, Brasília, v. 62, n. 2, p.137-166, jun. 2011.

. Um modelo e um plano de gestão do conhecimento e inteligência organizacional para administração pública brasileira. Revista Brasileira de Planejamento e Orçamento, Brasília, v. 4, n. 1, p.77-103, ago. 2014.

A Emergência da Reforma do Estado Brasileiro: a governança compartilhada e o modelo do novo serviço público. Planejamento e Políticas Públicas, Brasília, v. 21, n. 45, p.13-46, dez. 2015.

AUSTRALIAN INSTITUTE FOR DISASTER RESILIENCE (AIDR). Handbook 8: lessons management. 2013.

About AIDR. Disponível em: <https://www.aidr.org.au/about-aidr/>. Acesso em: 10 ago. 2020.

BATISTA, Fábio Ferreira. Modelo de Gestão do Conhecimento para a Administração Pública Brasileira: Como implementar a Gestão do Conhecimento para produzir resultados em benefício do cidadão. Brasília: Ipea, 2012. $132 \mathrm{p}$.

. Gestão do Conhecimento na Administração Pública: Resultados da pesquisa IPEA 2014 - grau de externalização e formalização. Texto para discussão $n^{\circ}$ 2066. Brasília: IPEA, 2015.

BATISTA, Fábio Ferreira et al. Casos reais de implantação do Modelo Gestão do Conhecimento para a Administração Pública Brasileira: a experiência do governo de Minas Gerais. Texto para discussão n 2038. Brasília: IPEA, 2015.

BETAT, Silvio Pimentel. A gestão do conhecimento doutrinário e a evolução da doutrina. Doutrina Militar Terrestre em Revista, Brasília, v. 5, n. 10, p. 14-21, jan. 2017.

CARDOSO, Daniel et al. Gestão do Conhecimento nas respostas a desastres naturais: a experiência da Defesa Civil do Estado de Santa 


\section{Revista FLAMMAE}

Revista Científica do Corpo de Bombeiros Militar de Pernambuco

Artigo Publicado no Vol.06 N.17 - Edição Jul a Dez 2020 - ISSN 2359-4829

Versão on-line disponível em: http://www.revistaflammae.com

Catarina. Perspectivas em Gestão \& Conhecimento, João Pessoa, v. 4, n. 2, p.90-106, dez. 2014.

CHAVES, Tiago Costa. A aplicação da Gestão do Conhecimento no alcance dos objetivos estratégicos do Corpo de Bombeiros Militar do Estado de Goiás. 2015. 30 f. Monografia (Especialização) - Curso de Gerenciamento de Segurança Pública, Universidade Estadual de Goiás, Goiânia, 2015.

CODY, W. F. et al. The integration of businnes intelligence and knowlegde management. IBM Systems Journal, [s.i], v. 41, n. 4, p.697-713, 2002.

COELHO, Espartaco Madureira. Gestão do conhecimento como sistema de gestão para o setor público. Revista do Serviço Público, Brasília, v. 55, n. 2 , p.89-115, jun. 2004.

CORPO DE BOMBEIROS MILITAR DE ALAGOAS (CBMAL). Plano Estratégico 2020-2024. Maceió, AL, 2020.

CORPO DE BOMBEIROS MILITAR DO DISTRITO FEDERAL (CBMDF). Plano Estratégico 2017-2024. $1^{\text {a }}$ versão. Brasília, DF, 2016. Disponível em: $<$ https://www.cbm.df.gov.br/2012-11-12-17-42-33/2012-11-13-16-1457? task=document.viewdoc\&id=11718>. Acesso em: 23 mar. 2019.

CORPO DE BOMBEIROS MILITAR DO ESTADO DE GOIÁS (CBMGO). Portaria $n^{\circ}$ 205/2016 - CG. Nomeia Grupos de Trabalho para apoiar as ações de Gestão do Conhecimento no âmbito da corporação e dá outras providências. 2016.

. Gestão do Conhecimento. 2019. Disponível em:< https://www.bombeiros.go.gov.br/gestao-do-conhecimento>. Acesso em: 10 mai. 2019.

CORPO DE BOMBEIROS MILITAR DO ESPÍRITO SANTO (CBMES). Organograma. 2020. Disponível em: <https://cb.es.gov.br/organograma >. Acesso em: 10 ago. 2020

. Portaria $\mathrm{n}^{\circ} 429-\mathrm{R}$, de 09 de maio de 2017. Boletim do Comando $\overline{G e r a l ~}^{\circ}$ 019, de 11 de maio de 2017. Vitória, ES, 11 mai. 2017.

Corpo de Bombeiros realiza Seminário de Gestão do

Conhecimento. 2017. Disponível em:

$<$ https://cb.es.gov.br/Not\%C3\%ADcia/corpo-de-bombeiros-militar-realizaseminario-de-gestao-do-conhecimento>. Acesso em: 10 ago. 2020

DALKIR, Kimiz. Knowledge management in theory and practice. Oxford: 


\section{Revista FLAMMAE}

Revista Científica do Corpo de Bombeiros Militar de Pernambuco

Artigo Publicado no Vol.06 N.17 - Edição Jul a Dez 2020 - ISSN 2359-4829

Versão on-line disponível em: http://www.revistaflammae.com

Elsevier, 2005.

DAVENPORT, Thomas H.; PRUSAK, Laurence. Conhecimento empresarial: como as organizações gerenciam o seu capital intelectual. 10. ed. Rio de Janeiro: Elsevier, 2003.

EXÉRCITO BRASILEIRO (EB). Portaria n 1.150, de 08 de novembro de 2017. Aprova as Instruções Gerais para o Sistema de Doutrina Militar Terrestre (SIDOMT) (EB10-IG-01.005), 5a Edição, 2017, e dá outras providências. Separata ao BE n 46/2017. Brasília, 17 nov.2017. . Instruções reguladoras para a Gestão do Conhecimento Doutrinário (EB20-IR-10.003). 2. ed. 2015.

F. J. DE SOUZA; R. H. TREVISAN; J. A. S. SIQUEIRA. Gestão do conhecimento integrada aos sistemas inteligentes da Polícia Militar do Estado de São Paulo. Unisanta Law and Social Science, Santos, v.8, n.1, p. 179202, 2019.

FORÇA AÉREA BRASILEIRA (FAB). Instituto de Aplicações Operacionais (IAOP). Organograma. 2019. Disponível em:

<http://www2.fab.mil.br/iaop/index.php/organograma>. Acesso em: 23 abr. 2019.

GRANT, Robert M. Contemporary Strategy Analysis. 8. ed.. West Sussex: Wiley, 2013.

HEISIG, Peter. Knowledge Management in Public Administration in Four European Countries: Examples from Austria, Germany, Switzerland and United Kingdom. In: BATISTA, Fábio Ferreira (Org.). Experiências Internacionais de Implementação da Gestão do Conhecimento no Setor Público. Rio de Janeiro: IPEA, 2016. p. 139-173.

JANSEN, Alexandre Eduardo. Uma nova estrutura para a produção doutrinaria no Exército Brasileiro. Doutrina Militar Terrestre em Revista, Brasília, v.1, n.1, p. 7-15, jan. 2013.

LAPA, Jorge Eduardo Pimentel da; RODRÍGUEZ, Tomás Daniel Menéndez. Modelo de arquitetura de portal corporativo com ênfase à gestão do conhecimento. Ciência da Informação, Brasília, v. 45, n. 1, p.88-110, abr. 2016.

LAUSIN, Anthony; DESOUZA, Kevin C.; KRAFT, George D.. Knowledge management in the US army. Knowledge And Process Management, [s.I.], v. 10, n. 4, p.218-230, 2003. 


\section{Revista FLAMMAE}

Revista Científica do Corpo de Bombeiros Militar de Pernambuco

Artigo Publicado no Vol.06 N.17 - Edição Jul a Dez 2020 - ISSN 2359-4829

Versão on-line disponível em: http://www.revistaflammae.com

LIRA, Luiz Augusto de Medeiros. Gestão do Conhecimento no Setor

Público: uma proposta para o Corpo de Bombeiros Militar de Alagoas. 2019.

155 f. Dissertação (Mestrado) - Curso de Mestrado Profissional em

Administração Pública, Faculdade de Economia, Administração e

Contabilidade, Universidade Federal de Alagoas, Maceió, 2019.

LIRA, Luiz Augusto de Medeiros; LEMOS, Fabio Henrique Guttoski.

Administração Pública Gerencial, Gestão do Conhecimento e Comunidades de Prática: estudo de caso no Corpo de Bombeiros Militar de Alagoas. Revista

Flammae: Revista Científica do Corpo de Bombeiros Militar de Pernambuco, João Pessoa, v. 3, n. 8, p.97-125, dez. 2017.

LIRA, Luiz Augusto de Medeiros; PINTO, Ibsen Mateus Bittencourt Santana. Gestão do Conhecimento: perspectivas para o Corpo de Bombeiros Militar de Alagoas. In: Simpósio de Engenharia da Produção, 6., 2018, Salvador. Anais... Salvador: Even 3, 2018. p. 1 - 10.

MASSARO, Maurizio; DUMAY, John; GARLATTI, Andrea. Public sector knowledge management: a structured literature review. Journal Of Knowledge Management, [s.l.], v. 19, n. 3, p.530-558, 11 maio 2015.

MCADAM, Rodney; REID, Renee. A comparison of public and private sector perceptions and use of knowledge management. Journal Of European Industrial Training, [s.I.], v. 24, n. 6, p.317-329, ago. 2000.

MCDOWALL, Denise; RYNNE, Anita; TALBOT, Steven. The Australian Army's knowledge management strategy: a reflexive organizational approach to knowledge capture and sharing. Handbook Of Research On Knowledge Management, [s.I.], p.87-110, jan. 2014.

ORGANIZAÇÃO PARA COOPERAÇÃO E DESENVOLVIMENTO ECONÔMICO (OCDE). Conclusions from the results of OECD survey on knowledge management practices. Paris: OECD, 2003. Disponível em: <http://goo.gl/RfbXTn>. Acesso em: 05 jul. 2019.

PICKLES, Anne. A knowledge management infrastructure for the NSW Fire Brigades. The Australian Journal Of Emergency Management, [s.i], v. 19, n. 2, p.21-24, maio 2004.

POLÍCIA MILITAR DO ESTADO DE SÃO PAULO (PMESP). Plano de Comando 2018-2019. Disponível em: < http://www.policiamilitar.sp.gov.br/unidades/ccomsoc/planejamento/index.html >. Acesso em: 26 mar. 2019.

RUAN, Lian; GROVES, Adam. Illinois Firefighter Line of Duty Deaths Digital Image Collection Database: A Knowledge Management Initiative. Fire 


\section{Revista FLAMMAE}

Revista Científica do Corpo de Bombeiros Militar de Pernambuco

Artigo Publicado no Vol.06 N.17 - Edição Jul a Dez 2020 - ISSN 2359-4829

Versão on-line disponível em: http://www.revistaflammae.com

Technology, [s.I.], v. 49, n. 1, p.163-173, 2013.

SARQUIS, Aléssio Bessa et al. Gestão da Aprendizagem Organizacional: um Estudo no Corpo De Bombeiros Militar de Santa Catarina. Revista Eletrônica de Administração e Turismo, Pelotas, v. 9, n. 5, p.998-1016, dez. 2016.

SCHLESINGER, Cristina C. Barros et al. Gestão do Conhecimento na Administração Pública. Curitiba: Imap, 2008.

SEBA, Ibrahim; ROWLEY, Jennifer. Knowledge management in UK police forces. Journal Of Knowledge Management, [s.I.], v. 14, n. 4, p.611-626, 20 jul. 2010.

SEBA, Ibrahim; ROWLEY, Jennifer; DELBRIDGE, Rachel. Knowledge sharing in the Dubai Police Force. Journal Of Knowledge Management, [s.I.], v. 16, n. 1, p.114-128, 17 fev. 2012.

SILVA, Vinicius Santos. Gestão do conhecimento: a captação dos conhecimentos gerados pela área operacional do Corpo de Bombeiros Militar do Distrito Federal. 2013. 94 f. TCC (Graduação) - Curso de Bacharelado em Administração, Faculdade de Economia, Administração e Contabilidade Departamento de Administração, Universidade de Brasília, Brasília, 2013.

SILVEIRA, Roberto Martins da. Diretrizes para Implantação da Gestão do Conhecimento no Centro de Ensino da Polícia Militar do Estado de Santa Catarina - CEPM. 2013. 169 f. Tese (Doutorado) - Curso de Doutorado em Engenharia e Gestão do Conhecimento, Departamento de Engenharia e Gestão do Conhecimento, Universidade Federal de Santa Catarina, Florianópolis, 2013.

SORIANO, Érico; HOFFMANN, Wanda Machado Aparecida; ARAUJO, Camila de. Gestão do Conhecimento aplicado aos desastres naturais: o caso da Defesa Civil. Em Questão, Porto Alegre, v. 23, n. 3, p.209-229, set. 2017.

STRAUHS, Faimara do Rocio et al. Gestão do Conhecimento nas Organizações. Curitiba: Aymará Educação, 2012.

SVEIBY, Karl-erik; SIMONS, Roland. Collaborative climate and effectiveness of knowledge work - an empirical study. Journal Of Knowledge Management, [s.I.], v. 6, n. 5, p.420-433, dez. 2002.

SWAP, Walter et al. Using Mentoring and Storytelling to Transfer Knowledge in the Workplace. Journal Of Management Information Systems, [s.i], v. 18, n. 1, p.95-114, jun. 2001. 
TAKEUCHI, Hirotaka. Knowledge-Based View of Strategy. Universia Business Review, [s.i], v. 10, n. 40, p.68-79, set. 2013.

THE AUSTRALIAN ARMY. Land Warfare Doctrine 7-0: Trainning and education. 2018.

WENGER, E.; WENGER-TRAYNER, B. Communities of practice: A brief introduction. 2015. Disponível em: <http://wenger-trayner.com/wpcontent/uploads/2015/04/07-Brief-introduction-to-communities-of-practice.pdf>. Acesso em: 20 set. 2018

YAP, J.B.H., ABDUL-RAHMAN, H.; WANG, C.. Design change dynamics in building project: from literature review to a conceptual framework formulation, Journal of Surveying, Construction \& Property, v. 8, n. 1, p. 1-21, 2017. 